\title{
Percepção ambiental dos moradores sobre a utilização das águas do Açude no Distrito de Galante, Campina Grande, Paraíba
}

\section{Environmental perception of residents about the use of the dam's water in District of Galante, Campina Grande, Paraiba, Brazil}

\author{
Lazaro Ramom dos Santos Andrade ${ }^{1}$; Jane Arimércia Siqueira Soares ${ }^{2}$; Jessica Morais Braga Lyra ; \\ Marilia Zulmira Sena de Souza Andrade 4
}

${ }^{1}$ Doutorando em Recursos Naturais na Universidade Federal de Campina Grande, Campina Grande, Paraíba. vasmeiras@hotmail.com; ${ }^{2}$ Mestranda em Recursos Naturais na Universidade Federal de Campina Grande, Campina Grande, Paraíba. jane_arimercia@hotmail.com; ${ }^{3}$ Mestranda em Recursos Naturais na Universidade Federal de Campina Grande, Campina Grande, Paraíba. jessicabragaadm@ gmail.com; ${ }^{4}$ Mestre em Recursos Naturais na Universidade Federal de Campina Grande, Campina Grande, Paraíba. mariliazulmira@hotmail.com

\section{N O T A}

Recebido: 05/06/2018

Aprovado: 03/11/2018

Palavras-chave:

Percepção ambiental

Recursos Hídricos

Semiárido

Key words:

Environmental perception

Water resources

Semi-arid

\section{R E S U M O}

O estudo da percepção ambiental constitui uma ferramenta capaz de expor a realidade socioambiental de determinadas comunidades através da coleta de informações diretamente com os moradores que vivenciam os problemas, visto que evidencia ações, valores e opiniões, bem como conhecimentos culturais e hábitos. O objetivo deste trabalho foi avaliar a percepção ambiental dos moradores do Distrito de Galante, sobre a utilização das águas do Açude José Rodrigues após o racionamento ocorrido nos entre os anos de 2016 e 2017, uma vez que as águas deste reservatório estão impróprias para o consumo humano. A metodologia foi composta pela aplicação de um questionário semiestruturado contendo questões abertas e fechadas, sendo aplicado a 30 moradores residentes no entorno do açude José Rodrigues. Os resultados mostram que $60 \%$ dos moradores afirmaram utilizar as águas do açude no período do racionamento, sendo as águas utilizadas para consumo humano, dessedentação animal, atividades domésticas, etc. Constatou-se que após o fim do racionamento os moradores utilizavam as mesmas águas para dessedentação animal, recreação, pesca e irrigação. Além disso, o açude é utilizado como ponto turístico, movimentando a economia local. Entretanto, essas águas estão impróprias para o consumo humano e para a realização de atividades que dependam da potabilidade da água.

\section{A B S T R A C T}

The study of environmental perception is a tool capable of exposing the socioenvironmental reality of certain communities through the collection of information directly with the residents who experience the problems, since it highlights actions, values and opinions, as well as cultural knowledge and habits. The objective of this study was to evaluate the environmental perception of District of Galante residents on the use of José Rodrigues Water after the rationing occurred between 2016 and 2017, since the water of this reservoir is inappropriate for human consumption. The methodology was composed by the application of a semistructured questionnaire containing open and closed questions, being applied to 30 residents living in the surroundings of the José Rodrigues reservoir. The results shows that $60 \%$ of the inhabitants stated that they use the water reservoir during the rationing period, being the waters used for human consumption, animal watering, domestic activities, etc. It was found that after the end of the rationing the residents used the same waters for animal watering, recreation, fishing and irrigation. In addition, the weir is used as a tourist spot, moving the local economy. However, these waters are inappropriate for human consumption and for activities that depends on the potability of water.

busca forçada de outras fontes alternativas para suprir a carência hídrica.

A construção de açudes e represas são as principais formas de armazenar grandes volumes de água para posteriormente serem usadas no abastecimento público das 
cidades. Como exemplo, tem-se o Açude Epitácio Pessoa, pertencente à Bacia do Rio Paraíba, que abastece Campina Grande - PB e mais 18 cidades. A problemática da água na região semiárida brasileira, esta intrinsicamente ligada à condução das políticas hídricas, em especial, a universalização do acesso e uso da água para as famílias mais carentes, ou seja, a falta de acesso à água de qualidade e em quantidade nessas regiões não deve estar ligada apenas as condições climáticas, mas ao papel fundamental das políticas públicas (SILVEIRA et al., 2014).

Nessa região, comunidades afastadas dos rios perenizados e dos grandes açudes, sobrevivem da agricultura de sequeiro e da criação de ovinos e caprinos, abastecidas pela água acumulada em pequenos e médios açudes, cisternas e poços, em sua maioria, de águas salobras. Essas localidades não são abrangidas por ações de monitoramento da quantidade e da qualidade da água, acarretando o desconhecimento pela população local da ocorrência de contaminação dos corpos hídricos e dos problemas associados à contaminação (FIGUEIREDO et al, 2008).

Entretanto, os efeitos da seca têm sido mais presentes nas áreas onde falta gerenciamento dos recursos hídricos. Observa-se a existência de reservatórios construídos, onde as águas não são utilizadas, devido algum tipo de poluição por esgotos que as tornam impróprias para os usos múltiplos da população.

Neste contexto, a percepção dos problemas pelos moradores pode ser o ponto de partida para uma sociedade mais participativa. As percepções são resultantes das experiências vivenciadas, fazendo-os desenvolver atitudes diferentes a depender da vivência de cada um.

Assim, o estudo da percepção ambiental é uma ferramenta capaz de colher conhecimentos, valores e opiniões de atores sociais em torno do ambiente que os rodeiam, uma vez que cada ator reage e percebe o meio de forma diferente do outro.

Para isso, a compreensão das pessoas em torno de determinadas circunstâncias é indispensável para a melhoria de ações por parte do poder público e para a mudança de hábitos por parte da própria população (SUESS et al., 2013).

Neste sentido, o Distrito de Galante situa-se no município de Campina Grande-PB, onde o abastecimento público é realizado pelo açude de Boqueirão. Com a estiagem ocorreu à redução da captação da água deste reservatório, ocasionando o racionamento nas cidades e distritos abastecidos pelo manancial.

O racionamento ocorreu entre os anos de 2016 e 2017, provocando transtornos aos moradores. Esse fato fez com que muitos moradores passassem a utilizar as águas do açude José Rodrigues nas diversas atividades, sendo os principais usos: doméstico em geral, dessedentação animal, irrigação, recreação e consumo humano.

Entretanto, essas águas estão contaminadas ou poluídas podendo provocar inúmeras doenças na população. Esse trabalho buscou avaliar a percepção ambiental dos moradores do Distrito de Galante pertencente ao município de Campina Grande-PB, sobre a utilização das águas do açude José Rodrigues após o racionamento.

Nesta perspectiva, avaliar a percepção ambiental através dos atores diretamente relacionados ao ambiente constitui uma forma de analisar a realidade vivenciada pela população. Através destes, será possível vislumbrar como o poder público atua junto a determinadas comunidades e como estas reagem e percebem o meio ao seu redor.

\section{MATERIAL E MÉTODOS}

\section{Localização da Área de Estudo}

O Distrito de Galante, localizada a $12 \mathrm{~km}$ de Campina Grande-PB (Figura 1), possui cerca de 10 mil habitantes, limitando-se com as cidades de Massaranduba ao norte, Fagundes ao sul, Ingá ao leste e Queimadas ao oeste (IBGE, 2010).

Figura 1. Localização geográfica do Distrito de Galante no município de Campina Grande, Paraíba

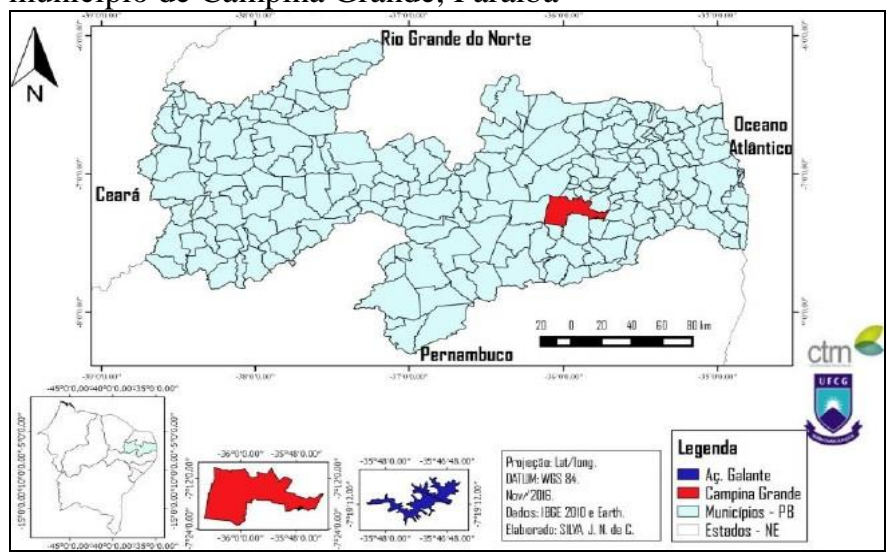

Fonte: Autores (2018).

O Distrito de Galante é abastecido pelas águas do açude Epitácio Pessoa, localizado no município de Boqueirão-PB. Com a estiagem a população de Galante passou a sofrer com o racionamento de água ocasionado pela diminuição da captação da água no açude de Boqueirão.

$\mathrm{O}$ distrito de Galante possui em seu perímetro o açude José Rodrigues com capacidade máxima de $22.332 .348 \mathrm{~m}^{3}$ de água (Figura 2). Durante a realização da pesquisa, o manancial contava com volume de $6.139 .790 \mathrm{~m}^{3}$, correspondendo a 27,49\% de sua capacidade (AESA, 2018).

Figura 2. Vista do Açude José Rodrigues no Distrito de Galante, Paraíba

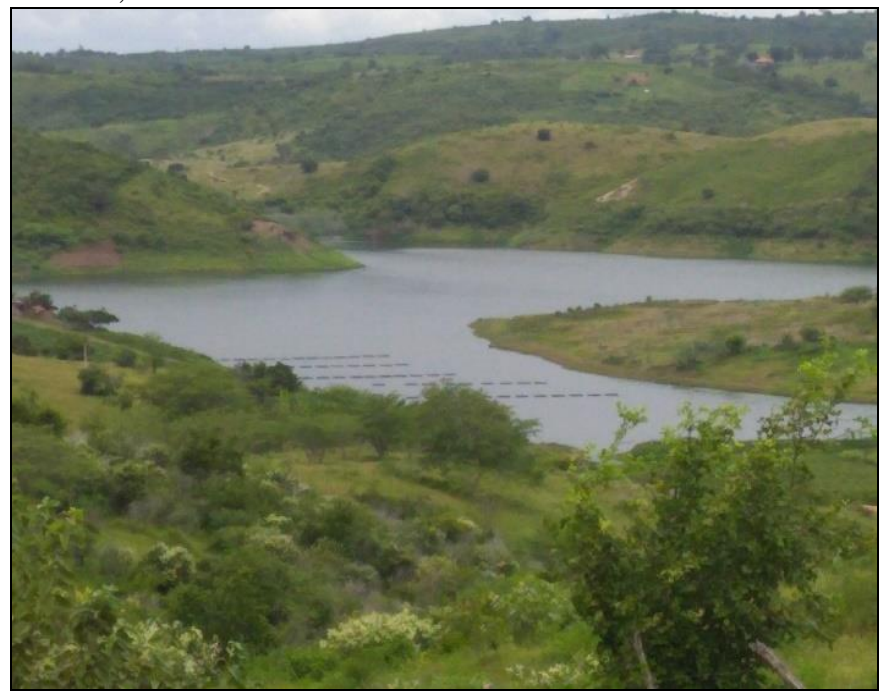

Fonte: Autores (2018).

Aspectos Metodológicos da Pesquisa

A metodologia empregada visa uma abordagem qualitativa, de modo que a sistemática utilizada se baseia na pesquisa descritiva e exploratória. 
O estudo descritivo descreve um fenômeno social que envolve estrutura, atividades, mudanças e relacionamentos com os demais fenômenos, são ainda mais relevantes quando apresentam informações acerca de temas pouco estudados, geralmente desenvolvem uma base de dados para possíveis trabalhos comparativos e de criação de teoria (GODOI et al., 2010).

A pesquisa exploratória permite maior familiaridade com o problema, tornando o mais explícito além de objetivar o aprimoramento de ideias e descoberta de intuições. Em muitos casos, envolve o levantamento bibliográfico, entrevistas com pessoas que tiveram vivência com o problema de pesquisa e a análise de exemplos que estimulem a compreensão (GIL, 2011).

Quanto aos fins, este estudo se caracteriza como explicativo, tendo em vista que o objetivo é explicar os motivos de algo e as suas causas, por meio do registro e da interpretação dos fenômenos observados (PRODANOV; FREITAS, 2013).

A pesquisa foi dividida em duas fases distintas. $\mathrm{Na}$ primeira etapa realizou-se a pesquisa de campo com visitas in loco ao perímetro do açude José Rodrigues, sendo realizada a aplicação de 30 questionários semiestruturados aos moradores da área, aplicados durante o mês de maio de 2018 (Quadro 1).

Quadro 1. Modelo de questionário aplicado.

Sexo: Masculino ( ) Feminino ( )

Escolaridade: Analfabeto ( ) Ensino fundamental incompleto ( ) Ensino fundamental completo ( )

Ensino médio incompleto ( ) Ensino médio completo ( ) Ensino superior incompleto ( ) Ensino superior completo ( )

Durante o racionamento você utilizou a água do Açude José Rodrigues? Se não, qual a fonte de abastecimento? Sim ( ) Não ( )

Em quais atividades o senhor (a) utilizava a água do Açude José Rodrigues?

Hoje após racionamento o senhor (a) utilizou a água do Açude José Rodrigues? Em quais atividades?

O senhor (a)acredita que essa água poderia ser utilizada para abastecer o distrito de Galante? Sim ( ) Não ( )

Na sua opinião quais os benefícios que serviço traria para a população?

Fonte: Autores (2018).

Esta etapa foi importante, pois foi possível conhecer a realidade local dos moradores e as necessidades relativas ao uso da água antes e depois do racionamento ocorrido entre os anos de 2015 e 2016.

Adicionalmente, também foram obtidas informações sobre os entrevistados, abordando aspectos socioeconômicos como idade e escolaridade.

$\mathrm{Na}$ segunda etapa foi realizado o estudo bibliográfico, que teve como propósito efetivar os resultados da pesquisa, sendo desenvolvida com base em material já elaborado, constituído principalmente de livros, artigos científicos, monografias e sites.

\section{RESULTADOS E DISCUSSÕES}

As principais variáveis avaliadas foram: sexo, idade, escolaridade, uso e utilização da água. De acordo com os dados apresentados a maioria dos entrevistados é do sexo feminino (55\%), sendo que a faixa etária variou entre 19 a 79 anos. A faixa etária dos entrevistados do sexo masculino variou ente 17 e 63 anos, correspondendo a $45 \%$.

Em relação à escolaridade não houve entrevistados analfabetos, de modo que o maior percentual foi de pessoas com ensino médio completo com $30 \%$, seguido do ensino fundamental incompleto com $26,8 \%$. As pessoas que afirmaram possuir ensino fundamental completo totalizaram $16,6 \%$, os entrevistados que apresentaram ensino médio incompleto correspondeu a $20 \%$. O percentual das pessoas que disseram possuir ensino superior foi de $6,6 \%$.

Diante da crise hídrica enfrentada pelo Estado da Paraíba nos últimos dois anos, muitos reservatórios diminuíram a capacidade de abastecimento. O Açude Epitácio Pessoa, localizado na cidade de Boqueirão-PB, responsável por abastecer a cidade de Campina Grande-PB juntamente com seus distritos, entre eles Galante, reflete o quadro vivenciado por esses mananciais.

O ano de 2016 compreende o estopim dessa crise, fato esse que se intensificam nas pequenas cidades, nas zonas periféricas, áreas rurais e distritais. Segundo Grande et al. (2016), o abastecimento de água urbano é vivenciado de modo diferenciado por diferentes estratos sociais.

As regiões periféricas assim como as comunidades rurais, são mais afetadas pela escassez de água, comprometendo o desenvolvimento de atividades econômicas, como a agropecuária (ARAÚJO, 2014). A Política Nacional do Meio Ambiente (1981), busca garantir através de um meio ambiente ecologicamente equilibrado a dignidade da pessoa humana, de modo que, a água representa um recurso básico da vida dos seres vivos, a sua falta fere esse direito.

Destaca-se que a escassez hídrica enfrentada pela região, bem como a carência de abastecimento público elucidam a carência de políticas públicas voltadas para o gerenciamento dessas águas.

Com base na vivência dos moradores quanto as dificuldades de abastecimento, o presente estudo buscou identificar como a população resolvia essa problemática. Questionados sobre a utilização da água do Açude José Rodrigues durante o racionamento $60 \%$ dos entrevistados responderam que utilizavam as águas do Açude para suprir suas necessidades básicas como beber e cozinhar. Entretanto, $40 \%$ das pessoas responderam que não utilizavam as águas do açude (Figura 3).

Esse cenário apresenta diversos conflitos socioambientais, tendo em vista que a população, em períodos de crise hídrica, ainda sofre com a redução ou falta de abastecimento, mesmo possuindo um manancial com capacidade suficiente para suprir a demanda local e, consequentemente, amenizar a problemática. 
Figura 3. Utilização da água do Açude José Rodrigues durante o racionamento pelos moradores de Galante.

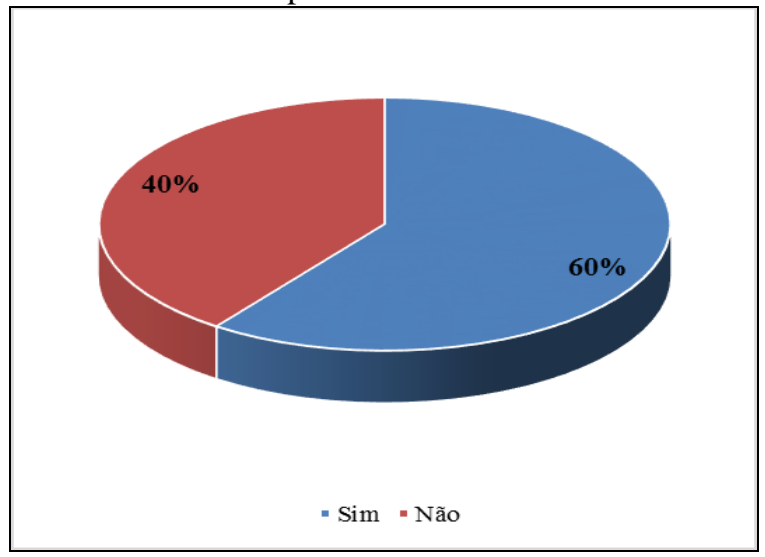

Segundo Andrade et al., (2018, p. 23), os conflitos socioambientais presentes na área de estudo transcendem os limites do município, uma vez que a falta de abastecimento público está ligada à redução do volume de água do açude Epitácio Pessoa, localizado na cidade de Boqueirão-PB.

Buscando conviver com a problemática da escassez hídrica a população buscou diversas alternativas. Entre os entrevistados $20 \%$ afirmaram possuir poço, $40 \%$ compravam água provinda de carros pipa, $20 \%$ faziam a captação da água da chuva, $20 \%$ racionavam ao máximo a água que chegava a torneira duas vezes por semana (Figura 4).

Figura 4. Estratégias utilizadas pela população para conviver com escassez hídrica.

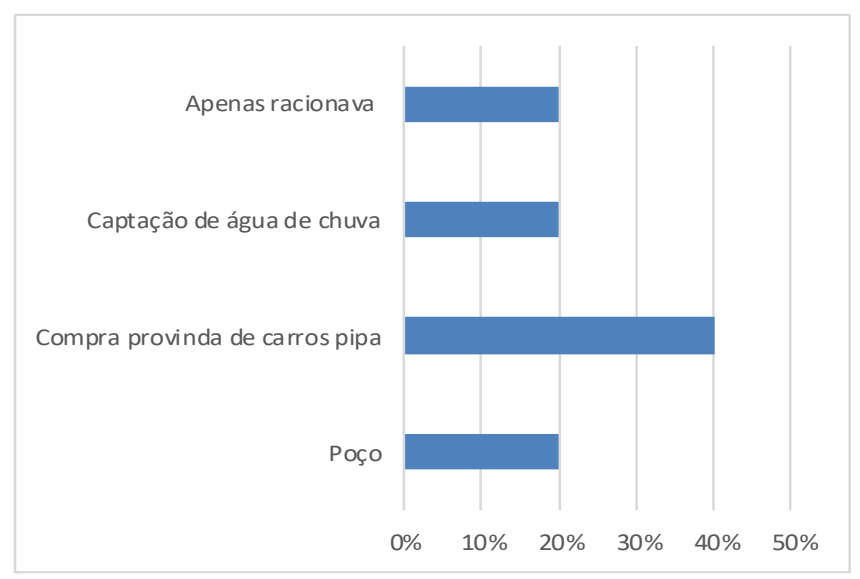

Diante da escassez desse recurso, a população fica vulnerável ao comércio da água, além da vulnerabilidade de diversos tipos de doenças, uma vez que na maioria das vezes não se conhece a procedência dessas águas. Dessa forma, a comercialização de água proveniente de carro pipa, o aumento na perfuração de poços e a construção de cisternas cresceram significativamente nos últimos dois anos no Distrito de Galante (ANDRADE et al., 2018).

Durante o período do racionamento, as águas do Açude José Rodrigues foram utilizadas pelos moradores para diversas finalidades. Salienta-se que os entrevistados responderam mais de uma opção, conforme a utilização. De acordo com os resultados constatou-se que essas águas desempenharam papel importante, sendo usadas nas atividades domésticas em geral, conforme a Tabela 1 .
Tabela 1. Usos da água do Açude José Rodrigues pela população durante o racionamento.

\begin{tabular}{cc}
\hline Usos da água & Percentual (\%) \\
\hline Lavar roupa & $100 \%$ \\
Limpeza em geral & $100 \%$ \\
Dessedentação animal & $70 \%$ \\
Cozinhar & $6,6 \%$ \\
Beber & $6,6 \%$ \\
Irrigação & $50 \%$ \\
Recreação & $40 \%$ \\
\hline
\end{tabular}

Com relação ao uso potável da água, 6,6\% dos entrevistados afirmaram terem consumido a água do reservatório e 6,6\% relataram ter feito o uso das águas para cocção dos alimentos. Vale salientar que antes de consumir a água os moradores não realizavam nenhum tratamento como cloração ou filtração. Conforme relatos dos moradores esse fato aconteceu durante os dois primeiros meses do racionamento.

Entre os entrevistados $50 \%$ faziam o uso das águas do manancial na irrigação, $70 \%$ para dessedentação animal e $40 \%$ para recreação. Sendo essa última atividade "bastante utilizada tanto pela comunidade local, como por turistas que visitam a área" (ANDRADE et al., 2018, p.25).

Quando perguntados sobre quais atividades eram destinados para o uso da água após o racionamento, 3 pessoas responderam utilizar as águas para a pesca, de modo que essa atividade representa a atividade econômica dessas pessoas. A recreação obteve nove respostas, recreação juntamente com a pesca foram oito, em seguida, a irrigação com cinco, dessedentação com quatro, pesca três respostas. (Figura 5).

Figura 5: Utilização da água do Açude José Rodrigues após o racionamento pelos moradores de Galante.

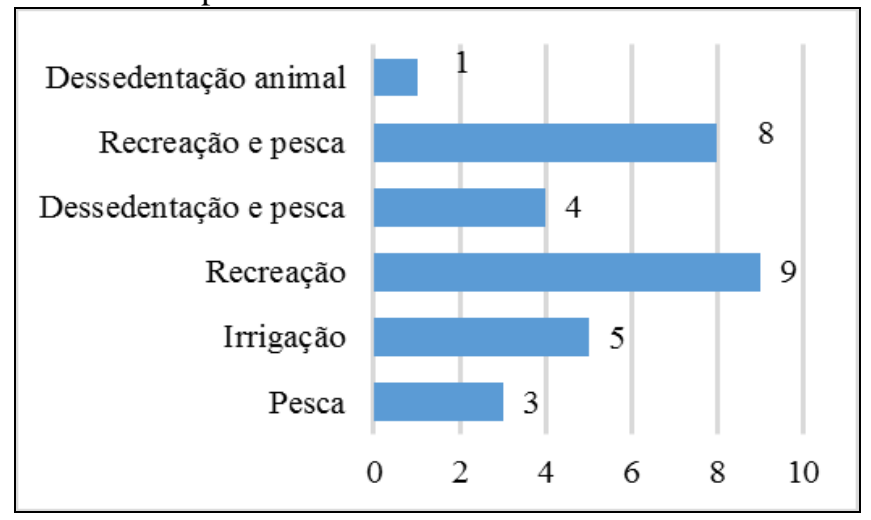

As atividades dos usuários das águas do Açude José Rodrigues estão mais voltadas para o lazer, a recreação e a pesca, do que atividades de manutenção, economia ou outra forma de uso com intenção de suprimento essencial. Áreas como essas destinadas ao lazer têm sofrido desvalorização, pois não são entendidos como essenciais, não tendo atenção necessária por parte das políticas públicas (FERREIRA et al., 2012).

A recreação e o turismo são atividades importantes nessa região, pois movimentam a economia local e representam um lazer acessível para as populações que vivem ao redor desse reservatório de água doce. Aos finais de semana é comum o banho nessas águas, principalmente para aqueles que utilizam dos bares e sítios para descanso ou diversão. 
Questionados sobre a possibilidade da utilização da água ser destinada para abastecer Galante, sete moradores relataram que não acreditam que o açude proporcione o abastecimento ao Distrito, contudo, vinte e três pessoas expuseram que concordam que a água poderia ser designada para suprir a região (Figura 6).

Figura 6. Utilização da água do Açude José Rodrigues pelos moradores do Distrito de Galante para abastecimento público local.

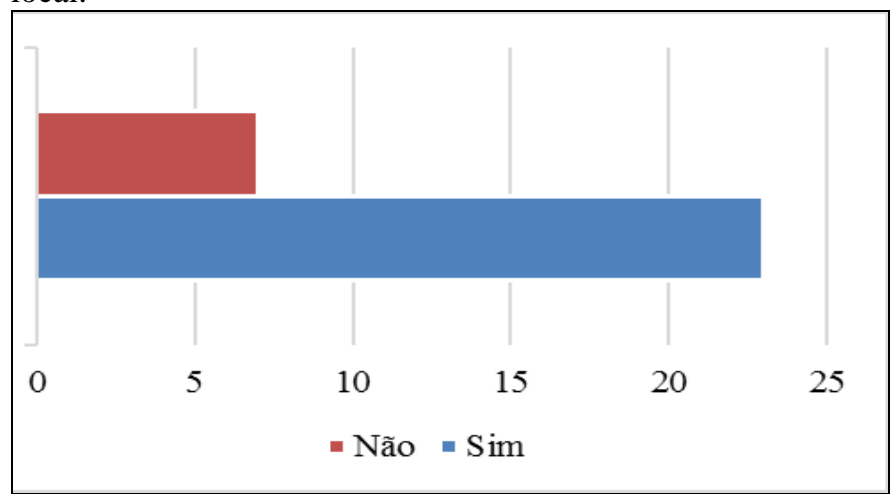

A construção de uma estação de tratamento nessa localidade possibilitaria a segurança hídrica para a população, além de reduzir o volume captado do Açude Epitácio Pessoa. Na Paraíba, existem diversas cidades com pequenos açudes que possuem uma quantidade considerável de água que poderiam ser utilizadas para suprir as necessidades locais.

Entretanto, as águas de muitos reservatórios estão impróprias para o consumo humano e em muitos casos para o uso doméstico. Isso ocorre devido ao lançamento de esgotos in natura e lixo nos corpos hídricos. Além disso, a falta de planejamento e de políticas públicas colaboram para a permanência dessa situação.

No Brasil, a Portaria 2914/2011 do Ministério da saúde (2011) dispõe sobre os procedimentos de controle e de vigilância da qualidade da água para consumo humano e seu padrão de potabilidade. $\mathrm{O}$ enquadramento das águas distribuídas nesses parâmetros deve ser rigorosamente fiscalizado para garantir a integridade física e saúde da comunidade (BRASIL, 2011).

A falta de acesso à água potável vem sendo apontada como a causa da maioria das enfermidades, de modo que atualmente, a preocupação com a proteção de áreas destinadas ao abastecimento público é eminente, pois a disponibilidade de água é cada vez menor (HAMEL, 2016). Segundo a ONU (2015), em 2025, duas em cada três pessoas não terão água para beber, em decorrência do consumo ser maior do que a natureza pode repor.

Essa problemática não se resume apenas à seca, mas também a problemas de ordem político-social. A efetivação de uma gestão pública eficiente pode ser considerada o primeiro passo, para mitigar diversos conflitos oriundos da falta de água, principalmente na região Nordeste.

Segundo Nascimento (2012), a falta de gestão e planejamento foi a responsável pelo conflito ocorrido em meados do século XX entre os distritos de Galante e a cidade de Fagundes, que enfrentavam problemas com a seca e falta de abastecimento.

A escassez hídrica é um problema que afeta a população nordestina, entretanto, a convivência com essa realidade mostra-se possível. O aproveitamento e o racionamento das águas são alternativas para diminuir a problemática. Neste sentido, a utilização das águas do açude José Rodrigues pode fornecer benefícios aos moradores do Distrito de Galante.

De acordo com os entrevistados, 60,8\% afirmaram que teriam mais dias com água na torneira, 4,4\% relataram que haveria redução na captação da água do açude de Boqueirão, $17,4 \%$ disseram que haveria a redução do racionamento pois essa água seria usada apenas pelos moradores locais e 17,4\% afirmaram que a água teria de melhor qualidade (Figura 7).

Figura 7. Principais benefícios de acordo com os moradores sobre a utilização da água do Açude José Rodrigues.

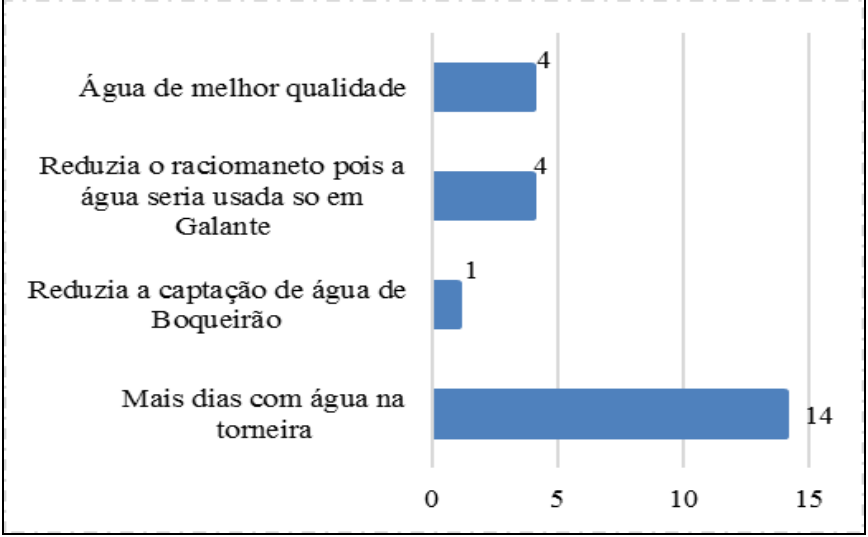

A utilização das águas do açude José Rodrigues é de suma importância para a população, porém sua qualidade deve estar de acordo com os padrões exigidos para os diversos fins a que se destina. A utilização para fins não potáveis devem seguir os padrões exigidos pela Resolução do Conselho Nacional do Meio Ambiente (CONAMA) n ${ }^{\circ} 357$ de 2005. Com relação a segurança dos banhistas a Resolução CONAMA n ${ }^{\circ} 274$ de 2000 dispõe os parâmetros exigidos para tal finalidade.

\section{CONCLUSÕES}

No racionamento os moradores utilizam as águas do açude José Rodrigues nas atividades domésticas, para consumo humano, recreação e irrigação. Além dessas atividades as águas do açude são utilizadas para o turismo e para a pesca movimentando a economia local.

Nessa área o conflito socioambiental é o mais evidente, pois o Açude José Rodrigues possui água suficiente para suprir as demandas dos moradores, contudo, percebe-se que a deficiência hídrica enfrentada pela região e a carência do abastecimento público é decorrente da falta de gestão ambiental e de políticas públicas voltadas para o gerenciamento dessas águas.

Ressalta-se que havendo um melhoramento quanto à Gestão direcionada para o uso da água do Açude, a comunidade estaria mais amparada e não dependeria de fontes externas para o abastecimento.

\section{AGRADECIMENTOS}

Os autores agradecem ao Programa de Pós-Graduação em Recursos Naturais pertencente à Universidade Federal de Campina Grande-PB pela oportunidade, bem como a Coordenação de Aperfeiçoamento de Pessoal de Nível Superior (CAPES) pela concessão da bolsa de mestrado e doutorado. 


\section{REFERÊNCIAS}

ARAÚJO, F. T. V.; NUNES, A. B. A.; SOUZA FILHO, F. A. Desertificação e pobreza: existe um equilíbrio de baixo nível? Revista Econômica do Nordeste, Fortaleza, v. 45, n. 1, p. 106119, jan./mar., 2014.

AESA. Agência Executiva de Gestão das Águas do Estado da Paraíba. Disponível em:

<http://site2.aesa.pb.gov.br/aesa/volumesAcudes.do?metodo= listarAcudesUltimaCota > Acessado em: 17/03/2018.

ANDRADE, L. R. S; LYRA, J. M. B; SOARES, J. A. S. Gestão do açude José Rodrigues, uma alternativa para mitigar a escassez hídrica no Distrito de Galante. Revista Ambientale, v. 1, n. 1, p. 16-28, maio 2018.

BRASIL. Resolução CONAMA 357. Brasília- DF. 17 de março de 2005.

BRASIL. Ministério da Saúde. Portaria 2914 de 12 de dezembro de 2011. Brasília, DF, 2011.

BRASIL. Política Nacional do Meio Ambiente. Lei 6.938 de 31 de agosto de 1981.

BRASIL. Resolução CONAMA 274. Brasília- DF. 29 de novembro de 2000.

FERREIRA, R. C.; LOPES, W. G. R.; ARAÚJO, J. L. L. A água como suporte para atividades de lazer e turismo: possibilidades e limitações da Barragem Piracuruca no Estado do Piauí (Brasil). RAEGA. p. 134-163, 2012.

FIGUEIREDO, M.C.B.; VIEIRA, V. P. P. B.; MOTA, S.; ROSA, M. F.; ARAÚJO, L. F. P.; GIRÃO, Ê.; DUCAN, B. L. Monitoramento comunitário da qualidade da água: uma ferramenta para a gestão participativa dos recursos hídricos no semi-árido. Revista de Gestão de Água da América Latina. Porto Alegre, v.5, n.1, p.51-60. 2008.

GRANDE, M. H. D.; GALVÃO, C. O.; MIRANDA, L. I. B.; SOBRINHO, L. D. G. A percepção de usuários sobre os impactos do racionamento de água em suas rotinas domiciliares. Ambiente \& Sociedade. São Paulo v. XIX, n. 1. p. $165-184.2016$

GIL, A. C. Como elaborar projetos de pesquisa. 4. ed. São Paulo: Atlas, 2011

GODOI, C. K.; MELLO, R; SILVA, A. Pesquisa qualitativa em estudos organizacionais - paradigmas, estratégia e métodos. 2. ed. São Paulo: Saraiva, 2010.

HAMEL, E. H; GRUBBA, L.S. Desafios do desenvolvimento sustentável e os recursos naturais hídricos. Revista Brasileira de Direito. 12(1): 100-111, jan.-jun. 2016.

IBGE, Instituto Brasileiro de Geografia e Estatística. Cidades. Disponível em:

<http://ibge.gov.br/cidadesat/painel/painel.php?lang=\&codmu $\mathrm{n}=250400 \&$ search $=$ paraiba|cam pina-grande|infograficos:dados-gerais-do-municipio> Acessado em: 10/3/2018.
NASCIMENTO, F. A. A barragem Francisco dos Reis no município de Fagundes-PB. Trabalho de Conclusão de Curso (Graduação em Geografia) - Universidade Estadual da Paraíba. 2012.

ONU. Organização das Nações Unidas. Relatório Mundial das Nações Unidas sobre Desenvolvimento dos Recursos Hídricos: Água para um mundo sustentável. 2015. Disponível em:< http://www.unesco.org/water/wwap > acessado em: $17 / 03 / 2018$

PRODANOV, C. C.; FREITAS, E. C. Metodologia do trabalho cientifico: métodos e técnicas da pesquisa e do trabalho acadêmico. 2ed. Novo Hamburgo: Feevale, 2013.

SILVEIRA, S. M. B.; CORDEIRO, R.; CLEMENTINO, R. A condução das políticas hídricas para o Semiárido Brasileiro: a ação do Estado e as lutas sociais. Emancipação, Ponta Grossa, 14(2): 249-259, 2014.

SUESS, R. C.; BEZERRA, R. G.; SOBRINHO, H. C. Percepção Ambiental de Diferentes Atores Sociais Sobre O Lago do Abreu em Formosa - GO. HOLOS, Vol. 6. 2013. 